\title{
PROPRIEDADE INTELECTUAL, BIODIVERSIDADE E MUDANÇA CLIMÁTICA
}

\author{
INTELLECTUAL PROPERTY, BIODIVERSITY AND CLIMATE CHANGE
}

\section{Vladimir Garcia Magalhães*}

\begin{abstract}
Resumo:
A mudança do clima impacta a biodiversidade e esta, por sua vez, pode contribuir para a adaptação a este fenômeno pelo uso dos recursos genéticos para o desenvolvimento de novas variedades vegetais mais resistentes ao aquecimento global, as quais podem ser protegidas judicialmente nos diversos países pelo direito de propriedade intelectual na modalidade direito de patente ou na modalidade direito de proteção à variedade vegetal. Por esta razão os acordos internacionais relativos à biodiversidade (CDB), aquecimento global (CQMC), desertificação (CNUCD) e acesso aos recursos fitogenéticos (TIRFAA) e os acordos internacionais relativos à propriedade intelectual estão relacionados entre si, o que tem gerado um processo de articulação entre estes acordos. Conclui-se, contudo, que algumas emendas em seus textos são necessárias para que este processo de articulação seja de fato eficaz e positivo para a adaptação à mudança do clima e mitigação dos seus efeitos.

Palavras-chave: Propriedade intelectual. Direito de patentes. Variedades vegetais. Biotecnologia. Biodiversidade. Mudança de clima. Aquecimento global. Recursos genéticos. Direito Internacional.
\end{abstract}

\begin{abstract}
:
Climate changes impact biodiversity, which can influence the adaptation to that fact by the use of genetic resources in the development of new more resistant to global warming vegetable varieties, which can be judicially for the countries based on the intellectual property as a patent or by the right to protection to vegetable varieties. For this reason, international agreements about biodiversity (CDB), global warming (CQMC), desertification (CNUCD) and access to python genetic resources (TIRFAA) and international agreements about intellectual property are interrelated, what has created an articulation process among these agreements. The conclusion is that some amendments in their texts are required in order to give effectiveness to this articulation process and positive for the adaptation to the climate change and relieve of their effects.
\end{abstract}

Keywords: Intellectual property. Patent law. Vegetable varieties. Biotechnology. Biodiversity. Climate changes. Global warming. Genetic resources. International law.

\footnotetext{
Mestre e Doutor em Direito Civil pela Faculdade de Direito da Universidade de São Paulo. Professor do Curso de Mestrado em Direito, área de concentração Direito Ambiental, da Universidade Católica de Santos (UNISANTOS). Advogado e biólogo.
} 
1. Introdução

Atualmente, a mudança do clima e a perda de biodiversidade são os dois mais importantes desafios para a humanidade. Em 2007, o Dia Internacional da Diversidade Biológica, foi celebrado com o tema Biodiversidade e Mudança do Clima, destacando a interação entre estes dois fenômenos e a necessidade de analisar ambos, não como questões distintas mas sim como questões intrinsecamente relacionadas. ${ }^{1}$

Esta conexão entre ambos fenômenos resultam em uma crescente colaboração e sinergia entre algumas das mais importantes organizações e acordos internacionais existentes na atualidade como o Secretariado da Convenção-Quadro das Nações Unidas sobre Mudança do Clima (CQNUMC), o Painel Intergovernamental sobre Mudança do Clima (PIMC), a Organização das Nações Unidas para Agricultura e Alimentação (FAO), a Organização Meteorológica Mundial (OMM), o Programa das Nações Unidas para o Meio Ambiente (PNUMA), o Secretariado da Convenção sobre a Diversidade Biológica (CDB), o Secretariado da Convenção das Nações Unidas para o Combate à Desertificação, assim como organizações regionais. ${ }^{2}$

Além disso, o potencial dos recursos genéticos existentes na biodiversidade para desenvolver plantas mais resistentes e adaptadas à mudança climática suscitam questões relativas a direitos de propriedade intelectual.

Este trabalho tem o objetivo de analisar as interações entre a biodiversidade, particularmente os recursos genéticos, com a mudança de clima, e os direitos de propriedade intelectual relacionados a esta matéria.

2. Acordos internacionais sobre biodiversidade e mudança de clima

\subsection{A Biodiversidade e a CDB}

Nos anos 80, o movimento ambientalista e instituições científicas tinham apontado que uma importante perda de biodiversidade estava ocorrendo em taxas crescentes e por este motivo fizeram várias recomendações científicas e políticas, que estavam presentes no trabalho do Centro de Direito Ambiental da IUCN que enfatizava o valor econômico

\footnotetext{
SECRETARIADO DA CONVENÇÃO SOBRE A DIVERSIDADE BIOLÓGICA. Celebrations of the International Day for Biological Diversity 2007: Biodiversity and Climate Change. Montreal. 2007, p. 1.

2 ORGANIZAÇÃO DAS NAÇÕES UNIDAS PARA AGRICULTURA E ALIMENTAÇÃO. FAO and Climate. 2007. p. 1.
} 
e sustentabilidade da biodiversidade que teve grande impacto no Programa das Nações Unidas para o Meio Ambiente (PNUMA). ${ }^{3}$

Em 1987, o Conselho de Governo do PNUMA organizou um Grupo de Trabalho Ad Hoc de Especialistas em Diversidade Biológica que fizeram suas primeiras reuniões em novembro de 1988. Em 1990, O Conselho de Governo estabeleceu um Grupo de Trabalho Ad Hoc de Especialistas Técnicos e Jurídicos para preparar um acordo internacional para a conservação e uso sustentável da biodiversidade. Em fevereiro de 1991, um primeiro rascunho de convênio internacional foi analisado por um Comitê Intergovernamental de Negociações e em maio de 1992 o texto final da Convenção sobre a Diversidade Biológica (CDB) foi adotado em Nairóbi, capital do Quênia, na África ${ }^{4}$ e a convenção foi aberta para assinaturas na Conferência das Nações Unidas para o Meio Ambiente e o Desenvolvimento (CNUMAD), realizada entre 3 e 14 de junho de 1992 no Rio de Janeiro. ${ }^{5}$ O Brasil assinou a CDB em 06 de maio de 1992, aprovou seu texto através do Decreto Legislativo n. 02 de 03 de fevereiro de 1994 e o promulgou em 16 de março de 1998 através do Decreto n. 2.519 .

A biodiversidade é definida pela CDB, em seu art. $2^{\circ}$, como sendo "a variabilidade de organismos vivos de todas as origens, compreendendo, dentre outros, ecossistemas terrestres, marinhos e outros ecossistemas aquáticos e os complexos ecológicos de que fazem parte; compreendendo ainda a diversidade dentro de espécies, entre espécies e de ecossistemas".

Esta definição é importante porque chama a atenção sobre as várias dimensões da biodiversidade, incluindo a dimensão da diversidade genética a qual, por sua vez, resulta na diversidade de espécies e na diversidade de indivíduos dentro de cada espécie.

$\mathrm{O}$ art. $2^{\circ}$ da $\mathrm{CDB}$ define recursos genéticos como sendo o "material genético de valor real ou potencial" e material genético como sendo "todo material de origem vegetal, animal, microbiana ou outra que contenha unidades funcionais de hereditariedade". Estas por sua vez são os genes "que ocupam uma posição fixa (locus) no cromossomo. Os genes produzem seus efeitos direcionando a síntese de proteínas". 6

Os seres vivos da biodiversidade são fontes de recursos genéticos. Quanto maior a biodiversidade de um país maior será a variedade genética nele existente e, portanto, maior será a variedade de recursos genéticos deste país, pois maior será a probabilidade de se encontrar entre os genes existentes nesta biodiversidade, alguns capaz de auxiliar a

\footnotetext{
SECRETARIADO DA CONVENÇÃO SOBRE A DIVERSIDADE BIOLÓGICA. CBD 10th Anniversary: The Convention on Biological Diversity from Conception to Implementation. Montreal. 2004, p. 4.

4 Id. Ibid., p. 4.

5 Id. Ibid., p. 7.

6 ENCICLOPEDIA BRITANICA ON LINE. Disponível em: <http://www.britannica.com/eb/topic-228226/ gene>. Acesso em: 29 jan. 2008.
} 
resolver uma necessidade humana, como a necessidade de adaptação da sociedade humana à mudança do clima.

As taxas anuais de extinção das espécies têm variado muito ao longo do tempo, mas a taxa média tem sido, se forem considerados os dados arqueológicos, por volta de 2,5 espécies por ano. Entretanto, em 2001, a COB avaliou que as taxas de extinção recentes poderiam ser 100 ou 200 vezes maiores que esta taxa média. ${ }^{7}$ Isto significaria que atualmente entre 250 a 500 espécies de organismos estariam desaparecendo todos os anos. Em outras palavras, de 0,7 a 1,4 espécies estariam desaparecendo a cada dia da Terra.

Deve-se salientar que é muito provável que um número maior de extinções esteja ocorrendo, pelo fato do conhecimento científico sobre as espécies existentes no mundo ser ainda muito incompleto e altamente concentrado em vertebrados. ${ }^{8}$ Estima-se que $24 \%$ das espécies de mamíferos e $12 \%$ das espécies de pássaros estavam globalmente ameaçadas de extinção no ano $2000 .^{9}$

A Avaliação Ecossistêmica do Milênio $(\mathrm{AEM})^{10}$ por sua vez, afirmou que os seres humanos aumentaram as taxas de extinção das espécies nos últimos séculos. Nos últimos 100 anos foram bem documentadas 100 extinções de pássaros, mamíferos e anfíbios. Se forem incluídas as extinções não bem documentadas, mas altamente prováveis, esta taxa se torna mil vezes maior que as taxas históricas. ${ }^{11}$

Mesmo quando uma espécie não é totalmente extinta, uma significativa diminuição de indivíduos nas diferentes espécies, resulta necessariamente em uma significativa diminuição na diversidade genética existente em cada espécie e, portanto, uma diminuição na biodiversidade como um todo. Naturalmente que uma diminuição da diversidade genética nas espécies resulta na diminuição dos recursos genéticos potencialmente úteis para a adaptação à mudança do clima e também para a indústria farmacêutica desenvolver novos medicamentos.

Segundo a AEM, a diversidade genética em geral tem declinado globalmente, particularmente entre as espécies utilizadas na agricultura, como resultado da agricultura intensiva que utiliza grandes quantidades de pesticidas, herbicidas, irrigação, fertilizantes

\footnotetext{
SECRETARIADO DA CONVENÇÃO SOBRE A DIVERSIDADE BIOLÓGICA. Global Biodiversity Outlook. Montreal, 2001, p.71.

Id. Ibid.

Id. Ibid., p.73.

10 Esta pesquisa, promovida pela ONU foi realizada por 1.395 cientistas de 95 países. Ela foi lançada pelo Secretário Geral das Nações Unidas, Kofi Annan, em junho de 2001 e finalizada em março de 2005. Seu objetivo foi o de fornecer informações científicas à Convenção sobre Diversidade Biológica, Convenção sobre Combate à Desertificação, Convenção de Ramsar sobre Zonas Úmidas e à Convenção sobre Espécies Migratórias, assim como a múltiplos usuários no setor privado e na sociedade civil. Seus relatórios demonstraram os impactos negativos das atividades humanas no funcionamento do planeta.

11 WORLD RESOURCES INSTITUTE. Ecosystems and Human Well-being: Biodiversity Synthesis. Washington, DC: Island Press, 2005. p. 3-4.
} 
nitrogenados e sementes selecionadas. Este tipo de agricultura, denominada de Revolução Verde, foi desenvolvida por grandes empresas, a partir de 1943, e se tornou mais difundida, notadamente nos países desenvolvidos, a partir dos anos $60{ }^{12}$

A Revolução Verde, espalhada pelo mundo através do processo econômico e político denominado de "globalização", tem gerado uma substancial redução da diversidade genética das plantas e animais utilizados nos sistemas agrícolas diminuindo a adaptabilidade destas espécies às mudanças ambientais como a mudança de clima. ${ }^{13}$

Além disso, ela tornou ameaçada de extinção um terço das 6.5 mil raças ${ }^{14}$ de animais domesticados existentes, sendo que a extinção de uma espécie ou raça significa uma perda definitiva de um conjunto único de genes existente no planeta, reduzindo a capacidade adaptativa das espécies e limitando a possibilidade de recuperação de espécies cuja população de indivíduos se torne muito reduzida. ${ }^{15}$ Conseqüentemente, a perda de diversidade genética nas espécies domesticadas é muito negativa para a adaptação à mudança do clima.

2.2. As interações entre a Conferência sobre a Diversidade Biológica (CDB), a Conferência-Quadro das Nações Unidas sobre a Mudança de Clima (CQNUMC) e a Conferência das Nações Unidas para o Combate à Desertificação (CNUCD)

Várias decisões da Conferência das Partes (COP) da CDB refletem a preocupação do seu Secretariado e países signatários com a mudança de clima. Neste sentido, as Decisões V/3 e V/4 (COP5 realizada em 1999) que destacaram os riscos da mudança de clima para a biodiversidade, especialmente os corais de recifes e ecossistemas de florestas. Em 2001, um relatório da CDB, avaliou as relações entre a biodiversidade e mudança de clima. ${ }^{16}$

Em 2004, a Decisão VII/15 da COP7, estimulou as partes a tomarem medidas para gerirem os ecossistemas de modo a conservar a sua capacidade de resiliência (elasticidade) ${ }^{17}$ a eventos climáticos extremos, e a ajudarem a sociedade humana a mitigar e se adaptar à

${ }^{12}$ Id. Ibid., p. 4.

${ }^{13}$ Id. Ibid., p. 5.

${ }^{14}$ A raça, ou subespécie como é também chamada, é uma divisão taxonômica da espécie. Assim, uma espécie de organismo pode se subdividir em diferentes raças.

${ }^{15}$ WORLD RESOURCES INSTITUTE. Ecosystems and Human Well-being: Biodiversity Synthesis. Washington, DC: Island Press, 2005. p. 45.

${ }^{16}$ SECRETARIADO DA CONVENÇÃO SOBRE A DIVERSIDADE BIOLÓGICA. (CBDTechnical Series no. 10). Interlinkages between biological diversity and climate change. Advice on the integration of biodiversity considerations into the implementation of the United Nations Framework Convention on Climate Change and its Kyoto Protocol.Montreal, 2003. passim.

${ }^{17}$ Segundo o ecólogo ODUM a capacidade de elasticidade de um ecossistema "indica a capacidade de se recuperar quando o sistema é desequilibrado por uma perturbação. ODUM, Eugene P. Ecologia, Rio de Janeiro: Ed. Guanabara, 1988. p. 32. 
mudança de clima. Além disso, a COP7 convidou a Conferência das Partes da CQNUMC e da CNUCD para colaborarem com a CDB para combater a desertificação e outras formas de degradação da terra.

Em 2006, a COP8 destacou a importância dos países integrarem as considerações relativas à biodiversidade em todas as suas políticas, programas e planos nacionais relevantes em resposta à mudança de clima, e desenvolverem rapidamente instrumentos para a implementação de atividades de conservação da biodiversidade que contribuam para a adaptação das sociedades humanas à mudança de clima. Durante a COP8, o Grupo Técnico Ad Hoc de Especialistas em Biodiversidade e Mudança de Clima, apresentou um relatório técnico fornecendo orientação para os países promoverem sinergia entre suas atividades relacionadas à mudança de clima e à conservação e uso sustentável da biodiversidade.

A Decisão VIII/30 da COP8, também destacou a necessidade de se identificar atividades mútuas de apoio a serem conduzidas pelos Secretariados da CQNUMC, CNUCD e CDB, suas partes e organizações estatais importantes.

De 19 a 30 de maio de 2008, ocorreu em Bonn, Alemanha, a COP9, que tratou das interações entre a biodiversidade e mudança do clima em seu relatório final. Neste documento são feitas propostas para integrar a mudança de clima nos grupos de trabalho da CDB; elencadas opções para ações de cooperação mútua relativas à mudança de clima entre a CDB, CQNUMC e CNUCD; elencadas atividades que podem ser realizadas pelas Partes para promover a sinergia entre estas convenções; e também foi feita uma proposta para se criar um Grupo Técnico Ad Hoc de Especialistas em Biodiversidade e Mudança de Clima para fornecer para a CQNUMC informações relevantes sobre a biodiversidade. ${ }^{18}$

Em 2001, durante a COP6, parte II, em Bonn, na 14a reunião do Corpo Subsidiário para Aconselhamento Científico, Tecnológico e Técnico da CDB (CSACTT), foi discutida a proposta do seu presidente sobre a identificação das áreas potenciais de cooperação entre a CDB e a CQNUMC e, em razão disso, o CSACTT propôs a formação de um Grupo de Articulação Conjunta (GAC) entre os Secretariados da CDB e da CQNUMC e que se convidasse também o Secretariado da CNUCD para participar deste grupo de modo a aumentar a coordenação entre estas três convenções e explorarem futuras opções para posterior cooperação entre elas. Em agosto de 2001, o GAC foi criado, sendo constituído por membros dos corpos subsidiários científicos e pelos Secretariados destas convenções.

Em janeiro de 2004, durante o $5^{\circ}$ Encontro do GAC em Bonn, Alemanha, foram identificados itens prioritários para a articulação destas convenções: a adaptação à mudança

\footnotetext{
${ }^{18}$ SECRETARIADO DA CONVENÇÃO SOBRE A DIVERSIDADE BIOLÓGICA. Report of the Conference of the Parties to the Convention on Biological Diversity on the Work of its Ninth Meeting (UNEP/CBD/ COP/9/29). Bonn, 2008. p. 151-161.
} 
de clima e a capacidade de desenvolver e transferir tecnologia. Atualmente, o GAC está desenvolvendo várias atividades em conjunto que incluem programas de trabalho e preparação de relatórios.

\subsection{Relações entre a Mudança de Clima e a Biodiversidade}

A CQNUMC define em seu art. $1^{\circ}$ a "mudança de clima" como sendo aquela "que possa ser direta ou indiretamente atribuída à atividade humana que altere a composição da atmosfera mundial e que se some àquela provocada pela variabilidade climática natural observada ao longo de períodos comparáveis".

A mudança de clima já está provocando impactos significativos na biodiversidade e ecossistemas. Isto inclui mudanças nas distribuições geográficas das espécies, no tamanho de suas populações e em eventos ecológicos, como a época de reprodução ou migrações. Está também aumentando a freqüência de epidemias entre as espécies, ameaçando suas existências. No final do século, a mudança de clima pode ser o fator mais significante na perda de todos os elementos da biodiversidade como os biomas, os ecossistemas, as espécies e a diversidade genética. ${ }^{19}$

As crescentes taxas de mudança de clima resultam em crescentes danos na biodiversidade de todo o mundo. A mudança no clima projetada para 2050 pode resultar na extinção de $15 \%$ a 52\% de 1.103 espécies endêmicas, incluindo mamíferos, pássaros, anfíbios, répteis, borboletas e plantas. ${ }^{20}$

Este é um dado muito importante à medida que a AEM destacou que as diferentes espécies de microorganimos, plantas e animais, e seus genes, contribuem para o desenvolvimento de diversos e importantes produtos comerciais, como medicamentos, produtos para a proteção de plantas e lavouras, cosméticos, melhoramento de cultivos utilizados na agricultura, monitoramento ambiental. Em razão disto, existe uma crescente demanda da indústria de biotecnologia pela biodiversidade e seus recursos genéticos. ${ }^{21}$ Assim, pode-se concluir que as atividades de bioprospecção ${ }^{22}$ devem aumentar nas próximas décadas.

\footnotetext{
${ }_{19}$ WORLD RESOURCES INSTITUTE. Ecosystems and Human Well-being: Biodiversity Synthesis. Washington, DC: Island Press, 2005. p. 8-9 e 17.

${ }^{20}$ Id. Ibid., p. 56.

${ }^{21}$ WORLD RESOURCES INSTITUTE. Millennium Ecosystem Assessment. Ecosystems and Human Wellbeing: Synthesis. Washington, DC: Island Press, 2005. p. 109.

${ }^{22}$ Definida pela Medida Provisória 2.186-16, art. $7^{\circ}$, inc.VII, como sendo a "atividade exploratória que visa identificar componente do patrimônio genético e informação sobre conhecimento tradicional associado, com potencial de uso comercial".
} 
De fato, várias das maiores novas indústrias como a de biorremediação ${ }^{23}$ e biomimética, ${ }^{24}$ estão bem estabelecidas e aparentemente em expansão. $\mathrm{O}$ atual clima econômico sugere que a bioprospecção para a indústria farmacêutica irá aumentar, especialmente à medida que os novos métodos que utilizam conhecimentos de ecologia $\mathrm{e}$ evolução da vida tendem a aumentar a produtividade desta indústria. ${ }^{25}$

Neste cenário, é possível deduzir-se que a perda de biodiversidade em conseqüência da mudança de clima tende a aumentar o valor da biodiversidade remanescente, principalmente seus recursos genéticos e moléculas biológicas deles derivadas.

Portanto, a biodiversidade e a adaptação à mudança do clima, assim como a mitigação dos seus efeitos, estão intimamente relacionadas. A mitigação consiste na redução dos gases de efeito estufa enquanto a adaptação abrange as atividades para reduzir a vulnerabilidade dos sistemas humanos e naturais à mudança do clima. ${ }^{26}$

Em relação ao papel da biodiversidade para a mitigação da mudança de clima destaca-se que os ecossistemas terrestres, costeiros e marinhos, desempenham um importante papel no ciclo global do carbono, atuando como depósitos dos gases de efeito estufa à medida que podem seqüestrar estes gases da atmosfera. Deste modo, uma gestão adequada da biodiversidade que conserve e recupere estes ecossistemas são importantes medidas para a mitigação da mudança do clima. ${ }^{27}$

As plantas assimilam o carbono da atmosfera, fixando-o em seus tecidos à medida que crescem, portanto, de modo proporcional aos seus tamanhos. Por outro lado, a decomposição ou queima das plantas liberam carbono na atmosfera na forma de $\mathrm{CO} 2$, o mais importante gás de efeito estufa. Deste modo, o aflorestamento, ${ }^{28}$ o reflorestamento, ${ }^{29}$

${ }^{23}$ A biorremediação pode ser definida como todo o processo que usa microorganismos, fungos, plantas, algas verdes ou suas enzimas para que o ambiente contaminado retorne a sua condição original. Disponível em: $<$ http://pt.wikipedia.org/wiki/Biorremediação>. Acesso em: 20 jun. 2008.

${ }^{24}$ A biomimética é uma área da ciência que tem por objetivo o estudo das estruturas biológicas e das suas funções, procurando aprender com a Natureza e utilizar esse conhecimento em diferentes domínios da ciência. Disponível em: <http://pt.wikipedia.org/wiki/Biomimética>. Acesso em: 20 jun. 2008.

25 WORLD RESOURCES INSTITUTE. Millennium Ecosystem Assessment. Ecosystems and Human Wellbeing: Synthesis. Washington, DC: Island Press, 2005. p. 109.

${ }^{26}$ SECRETARIADO DA CONVENÇÃO SOBRE A DIVERSIDADE BIOLÓGICA. (CBDTechnical Series no. 10).Interlinkages between biological diversity and climate change. Advice on the integration of biodiversity considerations into the implementation of the United Nations Framework Convention on Climate Change and its Kyoto Protocol.Montreal, SCBD, 2003. p. iii.

${ }^{27}$ SECRETARIADO DA CONVENÇÃO SOBRE A DIVERSIDADE BIOLÓGICA. (CBDTechnical Series no. 10).Interlinkages between biological diversity and climate change. Advice on the integration of biodiversity considerations into the implementation of the United Nations Framework Convention on Climate Change and its Kyoto Protocol.Montreal, SCBD, 2003. p. iii e 3.

28 Significa plantar novas florestas em locais onde, historicamente, não existiam florestas.

${ }^{29}$ Significar plantar florestas em locais onde existiam previamente florestas que foram derrubadas para a conversão do solo para novos usos como a agricultura. 
e a redução de deflorestamento, ${ }^{30}$ são também importantes instrumentos para a mitigação da mudança do clima. ${ }^{31}$

O reflorestamento com espécies de árvores nativas é uma medida mitigatória positiva para a biodiversidade, mas o uso de espécies exóticas e pouco diversificadas é uma medida negativa para a biodiversidade e para o equilíbrio ecológico. Do mesmo modo, o aflorestamento pode resultar em grandes impactos ecológicos sendo por isso, por um lado, positivo para a mitigação da mudança do clima, mas simultaneamente, por outro lado, potencialmente negativo para a biodiversidade.

Efeitos positivos das atividades de adaptação à mudança do clima podem ser obtidos pela manutenção e restauração dos ecossistemas nativos; proteção e aumento dos serviços dos ecossistemas; ${ }^{32}$ desenvolvimento de sistemas agro-florestais e a preservação e respeito aos conhecimentos tradicionais. Por outro lado, as atividades de adaptação também podem ameaçar a biodiversidade diretamente, através da destruição de habitats, ou indiretamente através da introdução de novas espécies em determinados locais e ecossistemas. ${ }^{33}$

A conservação da biodiversidade e preservação das estruturas e funções dos ecossistemas são importantes estratégias para a adaptação à mudança de clima ${ }^{34}$ pelo fato das populações geneticamente diversas terem maior potencial de adaptação à mudança de qualquer tipo à medida que elas tem maior probabilidade de possuir entre seus membros um indivíduo com características biológicas que lhe permitem sobreviver nas novas condições do seu ecossistema.

Além disso, os genes relacionados a uma melhor adaptação à mudança de clima são recursos genéticos com grande valor para a indústria de biotecnologia desenvolver para a agricultura organismos geneticamente modificados para serem mais resistentes aos efeitos da mudança do clima.

O aquecimento do clima tende a tornar os solos mais secos e com maior salinidade. Novas plantas comerciais mais resistentes a estas condições podem ser desenvolvidas a partir de espécies mais tolerantes ao sal no solo (espécies halófitas) como a Salicornia spp e algumas Atriplex e Distichlis spp. ${ }^{35}$ Portanto, as plantas existentes em ecossistemas

\footnotetext{
${ }^{30}$ Destruição de florestas.

31 WORD RESOURCES INSTITUTE. Millennium Ecosystem Assessment. Ecosystems and Human Well-being: Biodiversity Synthesis. Washington, DC: Island Press, 2005, p.70 and 29.

32 Podemos conceituar "serviços dos ecossistemas" como as condições e processos que permitem a vida dos seres humanos no planeta, como a manutenção da concentração adequada de oxigênio na atmosfera, estabilização das condições climáticas, solo adequado para a agricultura, disponibilidade e preservação de recursos hídricos e outros.

33 WORD RESOURCES INSTITUTE. Millennium Ecosystem Assessment. Ecosystems and Human Well-being: Biodiversity Synthesis. Washington, DC: Island Press, 2005, p.8.

34 Id. Ibid.

35 SECRETARIADO DA CONVENÇÃO SOBRE A DIVERSIDADE BIOLÓGICA. Global Biodiversity Outlook. Montreal, 2001. p. 102.
} 
em áreas secas tendem a se tornar cada vez mais recursos genéticos preciosos, e deve-se destacar que no Brasil existe o bioma da caatinga com grande biodiversidade de espécies adaptadas ao clima mais quente e seco que podem ser no futuro recursos genéticos de grande interesse para outros países se adaptarem à mudança de clima.

De fato, a indústria de biotecnologia já está na corrida para criar para a agricultura, novas plantas mais resistentes à mudança do clima. Notícias, veiculadas, em 13 de janeiro de 2008, relatam que a Pioneer Hi-Bred International Inc, uma divisão da gigantesca empresa multinacional DuPont, está trabalhando muito e gastando milhões de dólares "equipando plantas para poderem manter a produtividade nos anos secos". Esta empresa está em uma corrida mundial, que envolve outras gigantescas empresas multinacionais que atuam na área da biotecnologia como a Monsanto e a Syngenta AG, para desenvolver, para a agricultura, novas variedades de milho, e outros cultivos, que consigam se desenvolver mesmo com um suprimento de água menor. Esta linha de pesquisa está se desenvolvendo com urgência adicional pelo fato dos cientistas preverem uma tendência de piora nas secas e aumento das temperaturas em todo o globo em razão da mudança do clima, sendo que os EUA já tiveram uma diminuição de $5 \%$ na produção de milho devido a secas que ocorreram no país em 2006 . $^{36}$

Deste modo, podemos observar que a biodiversidade, principalmente aquela existente em áreas mais quentes e secas, é a fonte de recursos genéticos para a indústria de biotecnologia desenvolver novas variedades vegetais, mais resistentes à mudança do clima. Isto ressalta a necessidade de se aumentar a efetivação internacional e em todos os países das disposições da $\mathrm{CDB}$ em relação ao consentimento prévio para o acesso aos recursos genéticos, e conhecimentos tradicionais associados, e a repartição de benefícios e ressalta também a necessidade de se agilizar e aprofundar a articulação da CDB com as organizações e acordos internacionais relativos à propriedade intelectual, inserindo neste processo as questões relativas à mudança do clima.

3. Acordos internacionais sobre propriedade intelectual e acessos aos recursos fitogenéticos e suas interações com a CDB

Os direitos de propriedade intelectual conferem um direito de exclusividade da pessoa sobre o uso de suas criações intelectuais por um certo período de tempo. Eles podem ser diferenciados classicamente em dois ramos.

\footnotetext{
${ }^{36}$ GILLAM, Carey (REUTERS). Biotech Companies race for Drought-Tolerant Crops. Disponível em: $<$ http:// www.boston.com/news/nation/articles/2008/01/14/biotech_companies_race_for_drought_tolerant_crops/>. Acesso em: 23 maio 2008.
} 
Um é o direito autoral (copyright) e direitos conexos, abrangendo os direitos dos autores sobre suas obras artísticas, literárias e científicas, como livros, e outras obras escritas, composições musicais, pinturas, esculturas, programas de computador, filmes assim como também os direitos dos atores, cantores e músicos sobre suas obras. ${ }^{37}$

$\mathrm{O}$ outro ramo do direito de propriedade intelectual é o direito de propriedade industrial, que abrange patentes de invenções, registro de marcas comerciais, indicações geográficas, desenhos industriais e segredos de comércio. ${ }^{38}$

Existem ainda sistemas de propriedade intelectual denominados de sistemas sui generis porque são distintos destes dois sistemas clássicos de propriedade intelectual. Estes novos sistemas abrangem os direitos de personalidade, circuitos integrados e o direito sobre novas variedades vegetai $\mathrm{s}^{39}$ que garante, a quem desenvolva uma nova variedade vegetal, o direito de exclusividade sobre o seu uso.

Porém, existe uma nova tendência de incluir também, entre os sistemas sui generis de propriedade intelectual, os conhecimentos tradicionais. Neste sentido, o atual esboço de texto do Acordo de Parceria Econômica entre os Países do Leste e Sul da África e a Comunidade Européia expressa isso no Título VI - Direitos de Propriedade Intelectual, art.64:

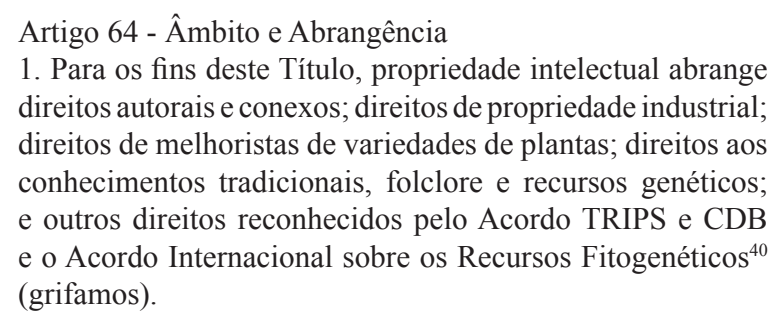

Esta inclusão está na realidade em consonância com o art.8(j) da $\mathrm{CDB},{ }^{41}$ que confere direitos às comunidades tradicionais sobre seus próprios conhecimentos, porque

\footnotetext{
37 Definição dada pela Organização Mundial do Comércio. Disponível em: $<$ http://www.wto.org/english/tratop_ e/trips_e/intel1_e.htm>. Acesso em: 04 fev. 2008.

38 Id. Ibid.

39 Id. Ibid.

40 No original: "Article 64- Scope and Coverage

1. For the purpose of this Title, intellectual property covers copyright and related rights; industrial property rights; plant breeders rights; rights to traditional knowledge, folklore and genetic resources; and other rights recognized under the TRIPS Agreement and CBD and the International Agreement on Plant Genetic Resources". Disponível em: <http://www.sarpn.org.za/documents/d0002205/index.php>. Acesso em: 12 maio 2008.

41 “Art.8. Conservação In Situ. Cada Parte Contratante deve, na medida do possível e conforme o caso: (...)

(j) Em conformidade com sua legislação nacional, respeitar, preservar e manter o conhecimento, inovações e práticas das comunidades locais e populações indígenas com estilo de vida tradicionais relevantes à conservação e à utilização sustentável da diversidade biológica e incentivar sua mais ampla aplicação com
} 
estas comunidades precisam aprovar previamente o uso destes conhecimentos por outras pessoas físicas ou jurídicas, o que é uma característica dos direitos de propriedade intelectual.

De fato, na maioria dos países desenvolvidos, como os EUA e países da União Européia, o direito de patentes permite patentear a estrutura química dos recursos genéticos, como são encontrados na Natureza, sem nenhuma alteração, assim como patentear as demais moléculas biológicas que deles derivam também sem qualquer alteração de suas estruturas químicas, portanto, sem a atividade inventiva que caracteriza uma invenção. ${ }^{42}$

Assim, os recursos genéticos, ou seus derivados, ${ }^{43}$ com potencial ou real uso para a adaptação da sociedade humana às mudanças do clima, podem ser patenteados nestes países e, caso os demais países desejem também utilizá-los, para a adaptação à mudança de clima ou outro fim, terão que negociar com os detentores destas patentes.

Por isso, e pelo fato dos genes existentes na biodiversidade poderem ser utilizados pela indústria biotecnológica para o desenvolvimento de novas variedades vegetais adaptadas à mudança do clima, o direito de propriedade intelectual torna-se importante elemento a ser considerado nas políticas internacionais e nacionais relativas à mudança do clima.

\subsection{O TRIPS e o Tratado de Cooperação em Matéria de Patentes (TCMP)}

O Acordo TRIPS (Agreement on Trade-related Aspects of Intellectual Property Rights), ${ }^{44}$ parte integrante do acordo internacional constitutivo da Organização Mundial do Comércio (OMC), tem o objetivo, segundo seu próprio texto, "de reduzir distorções e impedimentos ao comércio internacional, levando em conta a necessidade de promover efetiva e adequada promoção dos direitos de propriedade intelectual, e para garantir que medidas e procedimentos para fortalecer os direitos de propriedade intelectual não se tornem eles mesmos barreiras para o legítimo comércio". ${ }^{45}$

a aprovação e a participação dos detentores desse conhecimento, inovações e práticas; e encorajar a repartição eqüitativa dos benefícios oriundos da utilização desse conhecimento". (grifamos)

${ }^{42}$ MAGALHÃES, Vladimir Garcia. Propriedade Intelectual, Biotecnologia e Biodiversidade. 2005. 262 f. Tese (Doutorado) - Faculdade de Direito, Universidade de São Paulo, São Paulo. p. 138-147 e p. 239-241.

${ }^{43}$ Os produtos derivados dos recursos genéticos são as proteínas produzidas nos organismos a partir dos genes, assim como as demais moléculas biológicas, que por sua vez são produzidas por estas proteínas, como os alcalóides.

${ }^{44}$ Em português ADIPIC- Acordo sobre Aspectos dos Direitos de Propriedade Intelectual Relacionados ao Comércio. Foi utilizada no texto a sigla TRIPS em inglês pelo fato de ser mais utilizada nos textos acadêmicos e, conseqüentemente, mais conhecida.

45 Decreto n. 1.355/94, que aprovou a Ata Final que Incorpora aos Resultados da Rodada Uruguai de Negociações Comerciais Multilaterais do GATT, assinada em Marrakesh, em 12 de abril de 1994 aprovada no Brasil pelo Decreto Legislativo n. 30, de 15 de dezembro de 1994, Anexo 1-C. Disponível em: < https://www.planalto.gov. br/ccivil_03/decreto/1990-1994/anexo/andec1355-94.pdf>. Acesso em: 12 maio 2008. 
Entretanto, além de disciplinar os direitos de propriedade intelectual relacionados ao comércio, o TRIPS na realidade disciplina estes direitos em seu próprio conteúdo. Para exemplificar, o seu art. 27 disciplina o que é patenteável e o art. 28 disciplina os direitos conferidos pelas patentes, o que naturalmente não está relacionado ao comércio, mas a própria natureza deste instituto jurídico, o que deveria ser responsabilidade da Organização Mundial de Propriedade Intelectual (OMPI) e tratados que esta organização internacional administra.

A transferência de tecnologia destaca-se como um método para se alcançar um dos objetivos da CDB, conforme explicita seu art. 16.1, e ocorre que os direitos de propriedade intelectual constituem importante aspecto deste processo, uma vez que esta tecnologia pode ser protegida por alguma modalidade destes direitos, como a patente ou variedade vegetal. Além disso, como já vimos, os recursos genéticos e seus derivados podem ser objetos de patentes na maioria dos países desenvolvidos, criando para seus detentores direito de exclusividade sobre seu uso.

Por isso, o Secretariado da CDB solicitou para a OMC, através da comunicação datada de 13 de novembro de 2006, uma análise dos instrumentos legais nacionais, regionais e internacionais relacionados à propriedade intelectual que também se relacionassem de algum modo ao acesso aos recursos genéticos e repartição de benefícios pelo seu uso.

De acordo com o Secretariado da OMC as interações entre o TRIPS e CDB devem ser consideradas no processo consultivo para discutir as questões de implementação do TRIPS e também nos encontros regulares do seu Conselho. ${ }^{46}$ Algumas propostas têm sido discutidas nestes foros desde então.

Uma delas foi feita pelo grupo de países em desenvolvimento, liderados pela Índia, Brasil e Peru, para se emendar o TRIPS incluindo a obrigação, na solicitação de patente, de revelação de origem de recursos biológicos e conhecimentos tradicionais usados para desenvolver invenções assim como evidências do consentimento prévio para seu acesso e da repartição justa e eqüitativa dos benefícios pelo uso destes recursos biológicos e conhecimentos tradicionais. ${ }^{47}$

Outra proposta foi feita pela Noruega para se emendar o TRIPS de modo a introduzir um requisito obrigatório para revelação da fonte dos recursos genéticos e conhecimentos tradicionais ou seu país de origem, se este for conhecido, criando sanções fora do sistema de patentes caso isto não ocorra ou sejam fornecidas informações falsas. ${ }^{48}$

\footnotetext{
${ }^{46}$ SECRETARIADO DA CONVENÇÃO SOBRE A DIVERSIDADE BIOLÓGICA. Overview of Recent Developments at the International Level Relating to Acesso em and Benefit-Sharing. (UNEP/CBD/WGABS/5/4/Add.1), Montreal 30 August 2007. p.5.

${ }^{47}$ Id. Ibid., p.6.

${ }^{48}$ Id. Ibid.
} 
A União Européia (UE), por sua vez sugeriu que poderia ser incluído um requisito obrigatório de revelação da origem ou fonte dos recursos genéticos e conhecimentos tradicionais associados para concessão de patente, que poderia abranger todos os sistemas nacionais e internacionais de patentes, insistindo que os efeitos legais pelo nãocumprimento desta obrigação deveria ocorrer fora do sistema de patentes. ${ }^{49}$

O problema das propostas da Noruega e UE é que tornam o requisito de revelação de origem dos recursos genéticos, e conhecimentos tradicionais associados, ineficaz para a implementação dos objetivos da CDB, pois a exclusão no sistema de patentes das sanções pela recusa em revelar a origem ou mesmo o fornecimento de informações falsas resultaria na impossibilidade de se recusar a concessão de patente ou invalidação da mesma nestes casos.

Em 06 de junho de 2007, a Suíça, por sua vez, propôs emendar o Tratado de Cooperação em Matéria de Patentes (TCMP), ${ }^{50}$ para tornar explícito que as Partes neste tratado "podem" exigir dos solicitantes de patentes que revelem a origem do material genético, e conhecimentos tradicionais associados, no caso da invenção ser diretamente baseada neles. ${ }^{51} \mathrm{O}$ problema desta proposta é que não torna obrigatório para as Partes, exigirem isto.

Os EUA, apoiado por outros países desenvolvidos, por sua vez, foram contrários no Conselho do TRIPS a todas estas propostas alegando que um enfoque nacional utilizando soluções ajustadas às realidades de cada país, incluindo contratos, era suficiente para garantir os objetivos da CDB e que não ajudaria nem seria desejável envolver o sistema de patentes nisso. ${ }^{52}$

3.2. A Convenção da UPOV e o Tratado Internacional sobre Recursos Fitogenéticos para Alimentação e Agricultura (TIRFAA)

Além dos tratados relativos à patente, outros acordos internacionais, tendo por objetos outra modalidade de propriedade intelectual- as variedades vegetais ${ }^{53}$ e o uso dos

\footnotetext{
${ }^{49}$ Id. Ibid.

${ }^{50}$ Em inglês: Patent Cooperation Treaty (PCT). O termo Tratado de Cooperação em Matéria de Patentes é a tradução adotada pelo Instituto Nacional de Propriedade Industrial (INPI), órgão público responsável pela concessão de patentes e outras propriedades industriais. O TCMP entrou em força em 24 de janeiro de 1978 e estabelece um sistema internacional que permite a entrega em um único Escritório de Patentes de uma solicitação de patente em uma única língua que vai ter efeito nos demais países que são Partes no TCMP que o solicitante da patente especifique em sua solicitação.

51 SECRETARIADO DA CONVENÇÃO SOBRE A DIVERSIDADE BIOLÓGICA. Overview of Recent Developments at the International Level Relating to Acesso em and Benefit-Sharing. (UNEP/CBD/WGABS/5/4/Add.1), Montreal 30 August 2007. p. 5-6.

52 Id. Ibid., p. 6.

53 Também chamadas de obtenções vegetais.
} 
recursos fitogenéticos pelos países, se relacionam com a CDB. São eles a Convenção da UPOV e o TIRFAA.

A União Internacional para a Proteção de Obtenções Vegetais (UPOV) ${ }^{54}$ foi estabelecida pela Convenção Internacional para a Proteção de Novas Obtenções Vegetais, adotada em 2 de dezembro de 1961 e que entrou em força em 10 de agosto de 1968. Este acordo internacional foi revisado em 10 de novembro de 1972, 23 de outubro de 1978 e em 19 de março de 1991, de modo a refletir os novos desenvolvimentos tecnológicos utilizados para o melhoramento de plantas utilizadas na agricultura (cultivares) assim como a experiência adquirida com a sua aplicação ao longo deste período.

O Brasil aprovou seu texto em 20 de abril de 1999 através do Decreto Legislativo n. 28 e a promulgou em 30 de junho de 1999 através do Decreto n. 3.109, se tornando membro da UPOV em 29 de maio de 1999.

A Convenção UPOV define como sendo obtentor de um cultivar vegetal a pessoa ou seu empregador, que tenha criado ou descoberto uma variedade vegetal (art. $1^{\circ}$, iv) que é entendida como sendo um conjunto de plantas do nível taxonômico ${ }^{55}$ mais baixo conhecido (art. $1^{\mathrm{o}}$,vi).

Esta convenção disciplina os requisitos para a aquisição do direito de obtentor (capítulo 3, arts. $5^{\circ}$ ao $9^{\circ}$ ), o procedimento para a solicitação da concessão do direito de obtentor (capítulo 4, arts. 10 a 13), definindo esses direitos (capítulo 5, arts. 14 a 19) e o seu prazo de existência que é de, no mínimo, 20 anos e, no máximo, 25 anos para as árvores e videiras, contados a partir da data de concessão desse direito (art. 19).

Segundo Smolders, a "indústria de sementes (a Federação Internacional de Sementes) não tem problemas com a revelação de origem dos recursos genéticos de plantas utilizados no desenvolvimento de novas variedades de plantas". ${ }^{56}$ Isto foi estabelecido por esta organização em 2003 através do documento "Revelação de Origem na Aplicação da Proteção pela Propriedade Intelectual" e endossado por unanimidade no Congresso Mundial da Federação Internacional de Sementes em Bangalore, na Índia, no mesmo ano. ${ }^{57}$

Isto ocorre pelo fato das empresas de desenvolvimento de novas variedades vegetais avaliarem que não podem trabalhar com o risco de utilizar material que eles possam ter

\footnotetext{
${ }^{54}$ No original em inglês "International Union for the Protection of New Varieties of Plants (UPOV)".

55 Taxonomia é a ciência que classifica em grupos as plantas (taxonomia vegetal) e animais (taxonomia animal) conforme o grau de semelhança fenotípica (aparência dos indivíduos) e genotípica (referente ao conjunto de genes existentes no ser) entre os indivíduos.

${ }^{56}$ No original: "seed industry (the International Seed Federation) has no problems with disclosure of origin of plant genetic resources used in the development of new plant varieties".

57 SMOLDERS, Walter. Disclosure of Origin and Acesso em and Benefit Sharing: The special case of seeds for food and agriculture. Quaker United Nations Office. 2005. Disponível em: <http://www.iprsonline.org/ unctadictsd/docs/Disclosure_Smolders.pdf>. Acesso em: 04 fev. 2008.
} 
acessado de modo ilegal, pois isto poderia custar a eles uma fortuna, e os desenvolvedores são obrigados a anotar em seus livros de registros os materiais utilizados para desenvolver uma nova variedade vegetal.

Já a Organização das Indústrias de Biotecnologia, que é dominada pela indústria farmacêutica, é contra a revelação de origem dos recursos genéticos utilizados para o desenvolvimento de novos produtos biotecnológicos. ${ }^{58}$

O TIRFAA foi aprovado em Roma em 03 de novembro de 2001, assinado pelo Brasil em 10 de junho de 2002 e ratificado em 22 de maio de 2006. O Congresso Nacional aprovou este tratado através do Decreto Legislativo n. 70, de 18 de abril de 2006, e o Poder Executivo o promulgou pelo Decreto n. 6.476 de 05 de junho de 2008 .

Nos termos do art. $2^{\circ}$, do TIRFAA, se entende por recursos fitogenéticos para a alimentação e a agricultura "qualquer material genético de origem vegetal com valor real ou potencial para a alimentação e a agricultura".

Este tratado cria um Sistema Multilateral de Acesso e Repartição de Benefícios (SMARB) criado "tanto para facilitar o acesso aos recursos fitogenéticos para a alimentação e a agricultura quanto para repartir, de forma justa e eqüitativa, os benefícios derivados da utilização desses recursos, em base complementar e de fortalecimento mútuo". ${ }^{59}$ Este sistema abrange os recursos fitogenéticos listados no Anexo I do tratado que estão sob o controle das Partes e em domínio público.

Abrange também as coleções ex situ dos Centros Internacionais de Pesquisa Agrícola do Grupo Consultivo sobre Pesquisa Agrícola Internacional (GCPAI), ${ }^{60}$ o qual é uma estratégica parceria de países; organizações internacionais e regionais e fundações privadas que apóiam o trabalho dos 15 Centros estabelecidos em 1971.

Contudo, deve-se salientar que o Anexo I somente lista os gêneros das plantas utilizadas tradicionalmente pela agricultura. Assim, se uma nova variedade de planta for desenvolvida pela engenharia genética utilizando-se genes de espécies de plantas existentes na natureza pertencentes a diferentes gêneros daqueles listados no Anexo I, e que tem também natureza de recursos fitogenéticos nos termos do art. $2^{\circ}$, do TIRFAA, não será possível o controle de origem destes recursos fitogenéticos.

A Convenção UPOV se relaciona, portanto, com a CDB pelo fato de poderem ser utilizados recursos genéticos da biodiversidade no desenvolvimento de novas variedades vegetais, e a inserção, no procedimento para concessão do direito sobre nova variedade vegetal, da revelação de origem dos recursos genéticos eventualmente utilizados no desenvolvimento desta nova variedade contribui para a implementação da CDB.

\footnotetext{
58 Id. Ibid.

59 TIRFAA, art.10.2.

${ }^{60}$ Idem art.11.5.
} 
O TIRFAA por sua vez se relaciona com a CDB pelo fato de tratar também de acessos e repartição de benefícios pelo uso de recursos genéticos, porém somente os recursos genéticos de plantas utilizadas na agricultura. Como estas plantas podem conter recursos genéticos de plantas selvagens, existe uma necessidade de se garantir no âmbito do TIRFAA que as determinações da CDB de acesso previamente consentido aos recursos genéticos sejam cumpridas.

\section{Conclusão}

A biodiversidade está extremamente relacionada à mudança do clima à medida que, por um lado, o desflorestamento e destruição dos ecossistemas contribuem para aumentar e acelerar a mudança do clima e, por outro lado, o reflorestamento, a recuperação e conservação dos ecossistemas contribuem para mitigar o aquecimento global.

Além disso, biodiversidade, ao nível dos recursos genéticos, é extremamente importante para o desenvolvimento de novos organismos para a agricultura mais adaptados à mudança do clima e já está sendo utilizada para este fim, sendo que podem ser objetos dos direitos de propriedade intelectual como patentes e variedades vegetais.

A perda de biodiversidade, incluindo no seu nível de diversidade genética, tende a aumentar o seu valor econômico como fonte de material genético, e outras moléculas biológicas, que constituem matéria-prima para a indústria de biotecnologia desenvolver organismos mais adaptados à mudança do clima. Isto, associado a uma efetiva repartição de benefícios entre os países que fornecem estes recursos e os que o utilizam, pode estimular os países megadiversos a adotar medidas mais efetivas para a conservação da sua biodiversidade e mesmo para a recuperação da mesma, contribuindo assim para a mitigação da mudança do clima.

\subsection{Questões críticas}

Os recursos genéticos já estão sendo utilizados pela indústria de biotecnologia para desenvolver plantas para a agricultura, mais adaptadas à mudança do clima.

A CDB, em seu processo de articulação internacional com a CQNUMC e CNUCD, não está considerando, como seria desejável, os direitos de propriedade intelectual e sua relação com a mudança do clima e biodiversidade. Neste sentido seria interessante envolver os acordos e organizações internacionais em matéria de propriedade intelectual na articulação entre a CQNUMC, CDB e CNUCD para se discutir uma cooperação para a mitigação e adaptação à mudança do clima. Infelizmente, na COP9 da CDB em 2008, essa questão não foi abordada.

Uma implementação internacional mais efetiva dos objetivos da CDB quanto ao acesso previamente consentido e repartição de benefícios, pode levar os países 
megadiversos a facilitar de modo diferenciado os procedimentos nacionais para permitir uma bioprospecção quando direcionada à adaptação e mitigação da mudança do clima.

\subsection{Recomendações}

$\mathrm{O}$ art. 15.1 da CDB deveria mencionar, de modo explícito, a obrigatoriedade da facilitação do acesso aos recursos genéticos para fins de adaptação e mitigação da mudança do clima condicionando-o ao cumprimento nos países beneficiados dos demais dispositivos da CDB, particularmente o acesso previamente consentido aos recursos genéticos, seus derivados e conhecimentos tradicionais associados assim como a repartição de benefícios pelo seu uso.

A CDB, CQNUMC e CNUCD deveriam tomar medidas para se articularem com a Organização Mundial do Comércio (OMC), Organização Mundial da Propriedade Intelectual (OMPI) e União para a Proteção das Obtenções Vegetais (UPOV) para adotarem medidas para que os direitos de propriedade intelectual contribuam para a mitigação da mudança do clima e adaptação aos seus efeitos incluindo o TIRFAA neste processo. Além disto, os acordos internacionais sobre propriedade intelectual TRIPS, TCMP e Convenção UPOV deveriam ser emendados para inserir a obrigação de revelação de origem do recurso genético e conhecimentos tradicionais associados utilizados no desenvolvimento de uma nova invenção ou variedade vegetal, porém com sanções dentro do sistema de patentes caso não seja fornecida esta informação ou seja fornecida informação falsa.

O TIRFAA por sua vez poderia ser alterado para se criar um mecanismo que possibilitasse um controle de origem dos recursos fitogenéticos existentes na biodiversidade utilizados para se desenvolver novas plantas a serem cadastradas no Anexo 1 deste tratado.

Estas alterações, sugeridas, podem incentivar e facilitar o desenvolvimento de novas variedades vegetais a partir dos recursos genéticos da biodiversidade, e a conservação desta biodiversidade de modo a possibilitar uma melhor adaptação à mudança do clima e maior mitigação dos seus efeitos.

São Paulo, fevereiro de 2008.

\section{Referências}

DUBOVWY, Irene Ribeiro. Subsidies Code, Trips Agreement, and Technological Development: Some Considerations for Developing Countries. Journal of Technology Law \& Policy, v. 8, issue1, June 2003. Disponível em: < http://grove.ufl.edu/ techlaw/vol8/issue1/dubowy.html>. Acesso em: 05 fev. 2008. 
INTERGOVERNMENTAL PANEL ON CLIMATE CHANGE (IPCC). 16 Years of Scientific Assessment in Support of the Climate Convention. 2004. 14 p. Disponível em: <http://www.ipcc. $\mathrm{ch} /$ pdf/10th-anniversary/anniversary-brochure.pdf>. Acesso em: 24 mar. 2008.

MAGALHÃES, Vladimir Garcia. Propriedade Intelectual, Biotecnologia e Biodiversidade. 2005. 262 f. Tese (Doutorado) - Faculdade de Direito, Universidade de São Paulo, São Paulo.

ORGANIZAÇÃO DAS NAÇÕES UNIDAS PARA ALIMENTAÇÃO E AGRICULTURA. FAO and Climate. 2007. 7 p. Disponível em: <http://www.fao.org/clim/docs/FAO_and_Climate.pdf $>$. Acesso em: 21 mar. 2008.

. Biodiversity as a Source of Food Security. 2004. Disponível em: <http://www.fao.org/ regional/lamerica/en/dma/dma2004/biodiv.htm>. Acesso em: 31 jan. 2008.

. The International Treaty Becomes more Relevant to Global Climate Change, Food Security and Poverty Reduction. 2007. Disponível em: <ftp://ftp.fao.org/ag/agp/planttreaty/news/news0004 en.pdf>. Acesso em: 31 jan. 2008.

SMOLDERS, Walter. Disclosure of Origin and acesso em and Benefit Sharing: The special case of seeds for food and agriculture. 2005. Disponível em: <http://www.iprsonline.org/unctadictsd/docs/ Disclosure_Smolders.pdf $>$. Acesso em: 04 fev. 2008.

SECRETARIADO DA CONVENÇÃO SOBRE A DIVERSIDADE BIOLÓGICA. Analysis of Existing National, Regional and International Legal Instruments Relating to acesso em and BenefitSharing and Experience Gained in their Implementation, Including Identification of Gaps. (UNEP/ CBD/WG-ABS/3/2). Bangkok, 2005.

. CBD 10th Anniversary: The Convention on Biological Diversity from Conception to Implementation. Montreal. 2004.

- (CBDTechnical Series n. 10). Interlinkages between biological diversity and climate change. Advice on the integration of biodiversity considerations into the implementation of the United Nations Framework Convention on Climate Change and its Kyoto Protocol. Montreal, SCBD, 2003.

. Celebrations of the International Day for Biological Diversity 2007: Biodiversity and Climate Change. Montreal. 2007.

. Global Biodiversity Outlook. Montreal, 2001.

. Global Biodiversity Outlook 2. Montreal, 2006.

. Overview of Recente Developments at National and Regional Levels Relating to Acess and Benefit-Sharing. (UNEP/CBD/WG-ABS/5/4) Montreal, 2007.

. Overview of Recent Developments at the International Level Relating to Acess em and Benefit-Sharing. (UNEP/CBD/WG-ABS/5/4/Add.1), Montreal, 2007.

. Panorama da Biodiversidade Global 2. Montreal, 2006. 
. Report of the Ad Hoc Open-Ended Working Group on Acesso em And Benefit-Sharing on the Work of Its Third Meeting (UNEP/CBD/WG-ABS/3/7). Bangkok, 2005.

. Report of the Conference of the Parties to the Convention on Biological Diversity on the Work of its Ninth Meeting (UNEP/CBD/COP/9/29). Bonn, 2008. 